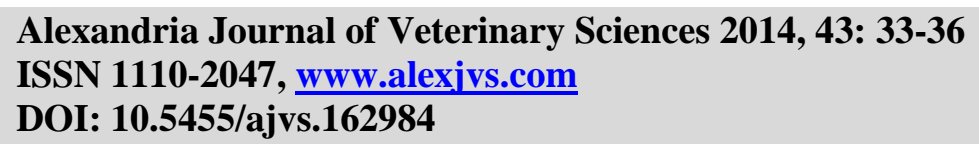

\title{
Effect of Infectious Bursal Disease Field Vaccines on Avian Influenza Vaccination Immunity
}

\author{
Shaimaa Ismael ${ }^{1}$, Mohamed M. Hamod ${ }^{2}$, Mohga F. Badawy, Manal M. Zaki ${ }^{1}$, Hamed A. Samaha ${ }^{3}$, Hassan \\ M. Elagrab ${ }^{1}$, Sherif T. Moubarak ${ }^{1}$, Osama K. Zahran ${ }^{1}$ \\ ${ }^{1}$ Dept. of Veterinary Hygiene and Management, Faculty of Veterinary Medicine, Cairo University, Egypt. \\ ${ }^{2}$ Dept. of poultry diseases, Faculty of Veterinary Medicine, Cairo University, Egypt \\ ${ }^{3}$ Dept. of Veterinary Hygiene and Zoonosis, Faculty of Veterinary Medicine, Alexandria University,
}

\begin{abstract}
Key words ABSTRACT:
IBD vaccine,

H5N1,

chickens

Traditional live Infectious Bursal Disease virus (IBDV) vaccines were thought to have some degree of adverse effect on the bursa of fabricous of chickens, which in turn may interfere with antibody production against other poultry vaccines. In this study, 15 broiler flocks vaccinated against avian influenza (AI) virus were sampled for serum. The flocks have received IBDV vaccination either from the conventional live vaccines or with the new recombinant subunit vaccine. Haemagglutination inhibition (HI) test was carried on sera using different AI antigens. Sera measured by the variant A/chicken/Egypt/VRLCU67/2011 (H5N1) isolate showed significant difference $(\mathrm{P}<0.05)$ between mean $\mathrm{HI}$ titers of bird vaccinated by traditional IBDV vaccines and titers of those vaccinated with the subunit vaccine. Results indicate that live IBDV vaccines may affect the efficacy of AI vaccine, and the study encourages the use of the field AI isolates for reliable interpretation of $\mathrm{HI}$ test results.
\end{abstract}

\section{INTRODUCTION}

It is likely that highly pathogenic avian influenza (HPAI) H5N1 virus infection among poultry had become endemic in Egypt Hagag et al (2014). Vaccination can be a useful tool for control of avian influenza outbreaks, but its efficiency may be affected by several factors in the field. An Immunosuppressive viral agent like the Infectious bursal disease (IBD) virus (IBDV) is one of the factors that affect the protection level obtained to poultry from vaccination in the field. Hence, "sterilizing immunity" is not feasible in the field. IBDV is the etiological agent of "Gumboro disease", infecting chickens, leading to lymphoid depletion, and ends by destruction of the bursa, and subsequently, reduces the chicken's immune response to vaccination (Müller et al., 2003; Swayne, 2006).

Vaccination of chickens against IBDV is mandatory and is a common practice in Egypt, where virulent and variant strains of the virus initiate mortality and immunosuppression leading to economic losses. However, the conventional whole attenuated IBD vaccines, which used in field carries the possible risk of bursal atrophy and immunosuppression (Pradhan et al., 2012).

A study carried out by Coletti et al., 2001 reported that the IBDV vaccine reduced the immunoresponse to NDV vaccine. Moreover, they detected histologic lesions in the bursa of Fabricius, in all chickens from 1 day of age which were similar in morphology to those caused by a field strain.

For that it was necessary to provide safer IBD vaccines for mass vaccination of chickens. OIE (2008) reported that beside the live attenuated and inactivated (killed) vaccines against infectious bursal disease (IBD), also a live recombinant vaccine expressing the VP2 antigen of IBD virus had been licensed a short time ago, which produced protective 
immune responses in chickens better than the available attenuated viral strains and its use was recommended as a vaccine for IBDV (Pradhan et al., 2012).

Vaxxitek ${ }^{\circledR}$ HVT + IBD is a new live vector vaccine, with the turkey herpesvirus (HVT) as carrier, allowing expression of viral protein-2 (VP2) of the IBD virus which is the main protective immunogenic component common to all known IBD strains. This vaccine could be administered by in ovo or day-old injection.

The aim of this study was to demonstrate the possible effect of the traditional IBD vaccines on the immune response of chickens to avian influenza vaccination in the field.

\section{MATERIAL AND METHODS}

\subsection{Broiler flocks:}

The study involved 15 broiler flocks that have received avian influenza vaccination at 7-11 days age through subcutaneous injection. In addition, the flocks have received infectious bursal disease (IBD) vaccination schedule as follows: (i) some flocks were vaccinated with the conventional live vaccines at age
14 and 22 days old by the hot ????or the intermediate strains at the first injection, while the $2^{\text {nd }}$ one was always by the intermediate strain. (ii) Other flocks were vaccinated with the new recombinant subunit vaccine "Vaxxitek ${ }^{\circledR}$ " at the time of hatch.

\subsection{Sample collection and preparation}

Blood was collected from the wing vein, allowed to clot and serum separated by centrifugation and stored at $-20^{\circ} \mathrm{C}$ until tested.

\subsection{Antigens used:}

For HI test, we used two AI antigens; the commercial Mexican H5N2 antigen and the previously isolated A/chicken/Egypt/VRLCU67/2011 (H5N1) antigen (clad 2.2.1.1/variant; accession no.: JX024234).

\subsection{HI test}

For HI test, we used 8 hemagglutinating units (HAU) of antigens, and $0.5 \%$ chicken RBC (cRBC) suspension (OIE, 2012). Mean HI titer values against AI were calculated, expressed as $\log 2$.

The results were statistically analyzed using SPSS 17.0 statistics software for the determination of significance at $\mathrm{P}<0.05$.

\section{RESULTS AND DISCUSSION}

Table 1: Avian influenza (AI) means HI titer of sera from broilers vaccinated with IBDV subunit "Vaxxitek ${ }^{\circledR}$ " vaccine and other conventional vaccines, using the Mexican H5N2 antigen:

\begin{tabular}{|c|c|c|c|}
\hline \multirow{2}{*}{$\begin{array}{c}\text { Age of AI } \\
\text { vaccination } \\
\text { (Days) }\end{array}$} & \multirow{2}{*}{$\begin{array}{l}\text { Age of } \\
\text { sampling } \\
\text { (Days) }\end{array}$} & \multicolumn{2}{|c|}{$\begin{array}{c}\text { Mean HI titer by H5N2 } \\
(\log 2) \pm \text { SE } \\
\end{array}$} \\
\hline & & $\begin{array}{c}\text { Subunit VP2 } \\
\text { vaccine }\end{array}$ & $\begin{array}{c}\text { Conventional } \\
\text { vaccine }\end{array}$ \\
\hline \multirow{3}{*}{$7-10$} & \multirow{3}{*}{$26-36$} & $1.38 \pm 0.53^{\mathrm{a}}$ & $2.50 \pm 1.41^{\mathrm{a}}$ \\
\hline & & $3.08 \pm 0.20^{\mathrm{a}}$ & $2.50 \pm 0.50^{\mathrm{a}}$ \\
\hline & & $5.00 \pm 0.87^{\mathrm{a}}$ & $4.38 \pm 0.84^{\mathrm{a}}$ \\
\hline \multicolumn{2}{|c|}{ Total HI means titer } & $3.08 \pm 0.22^{a}$ & $3.75 \pm 0.52^{\text {a }}$ \\
\hline
\end{tabular}

a-b Different superscripts indicate significant difference at $\mathrm{P}<0.05$ 


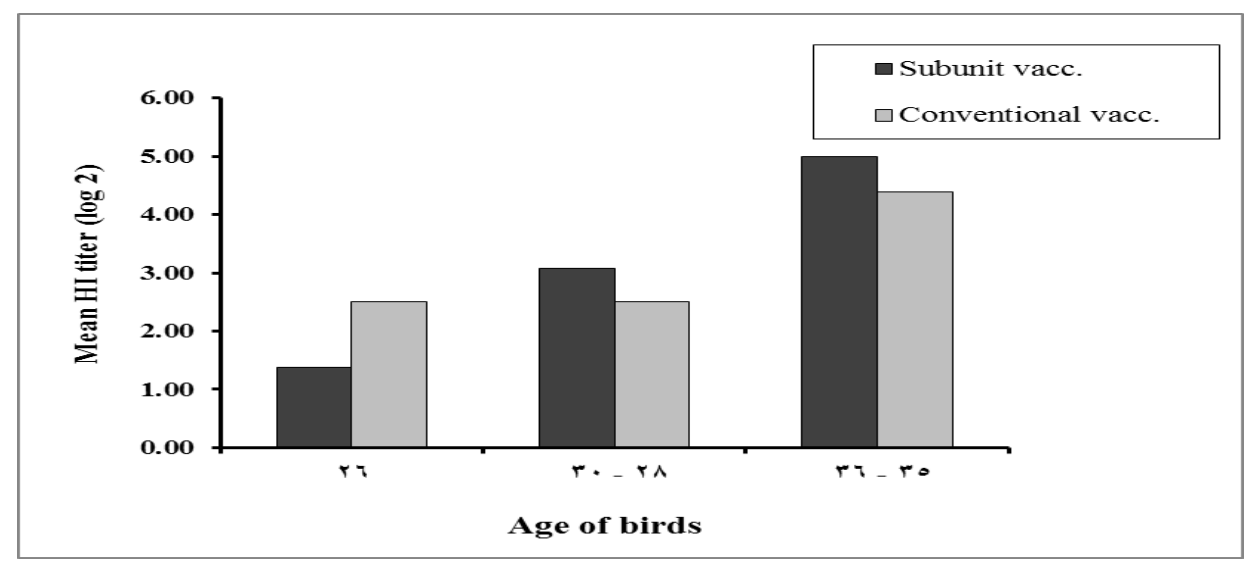

Fig (1): Avian influenza mean HI titers in sera of broilers vaccinated with the recombinant subunit vaccine "Vaxxitek ${ }^{\circledR}$ " and the conventional IBDV vaccines. HI test was worked with the commercial Mexican $\mathrm{H} 5 \mathrm{~N} 2$ antigen.

Table 2: Avian influenza mean HI titer of sera from broilers vaccinated with IBDV subunit "Vaxxitek®" vaccine and other conventional vaccines, using the variant A/chicken/Egypt/VRLCU67/2011(H5N1) antigen:

\begin{tabular}{|c|c|c|c|}
\hline \multirow{2}{*}{$\begin{array}{c}\text { Age of AI } \\
\text { vaccination } \\
\text { (Days) }\end{array}$} & \multirow{2}{*}{$\begin{array}{c}\text { Age of sampling } \\
\text { (Days) }\end{array}$} & \multicolumn{2}{|c|}{$\begin{array}{c}\text { Mean HI titer by VRLCU67/2011 (H5N1) } \\
(\log 2) \pm S E\end{array}$} \\
\cline { 3 - 4 } & \multirow{3}{*}{$26-36$} & $\begin{array}{c}\text { Subunit VP2 } \\
\text { vaccine }\end{array}$ & Conventional vaccine \\
\cline { 3 - 4 } $7-10$ & $4.50 \pm 0.42^{\mathrm{a}}$ & $3.00 \pm 0.68^{\mathrm{a}}$ \\
\cline { 3 - 4 } & & $5.76 \pm 0.16^{\mathrm{a}}$ & $3.25 \pm 1.03^{\mathrm{b}}$ \\
\cline { 3 - 4 } & & $5.57 \pm 0.37^{\mathrm{a}}$ & $4.13 \pm 0.44^{\mathrm{b}}$ \\
\hline \multicolumn{2}{|c|}{ Total HI means titer } & $5.58 \pm 0.14^{\mathrm{a}}$ & $3.50 \pm 0.38^{\mathrm{b}}$ \\
\hline
\end{tabular}

a-b Different superscripts indicate significant difference at $\mathrm{P}<0.05$

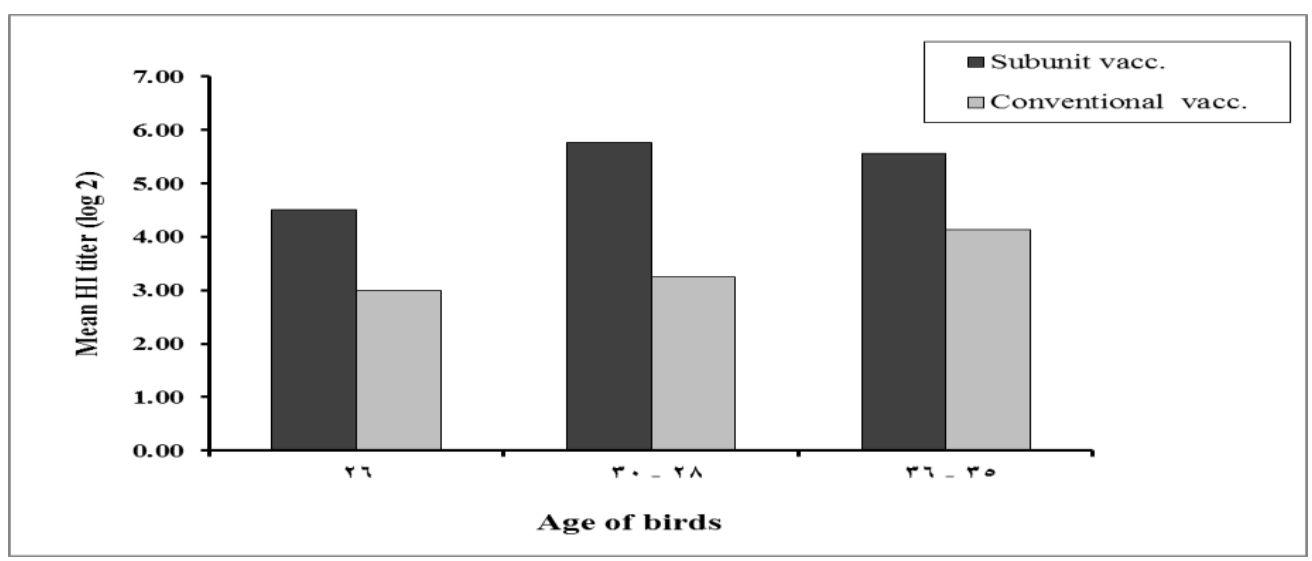

Fig (2): Avian influenza mean HI titers in sera of broilers vaccinated with the recombinant subunit vaccine "Vaxxitek®" and the conventional IBDV vaccines. HI test worked with the variant A/chicken/Egypt/VRLCU67/2011(H5N1) Egyptian isolate. 
Interference of different IBDV vaccines on immune response to AI vaccines was studied due to the potential immune-suppressive effect by IBDV live vaccines.

Results of $\mathrm{HI}$ test using Mexican H5N2 antigen recorded total mean $\mathrm{HI}$ titers of $3.08 \pm 0.22$ $\log 2$ and $3.75 \pm 0.52 \log 2$ for birds vaccinated with subunit IBDV vaccine and the conventional IBDV vaccines, respectively (fig. 1). Results show no significant difference between antibody titers produced in chickens vaccinated with any of those vaccines $(\mathrm{P}>0.05)$ (table 1$)$.

Mean HI titers measured by the variant $\mathrm{A} /$ chicken/Egypt/VRLCU67/2011(H5N1) isolate, recorded total mean of $5.58 \pm 0.14 \log 2$ and $3.50 \pm 0.38$ $\log 2$ for birds vaccinated with subunit IBDV vaccine and the conventional IBDV vaccines; respectively (fig. 2). Results show significant difference in the AI antibody titers between chickens vaccinated with IBDV subunit vaccine and the conventional ones $(\mathrm{P}<0.05)$ (table 2).

Results obtained by $\mathrm{HI}$ testing with the commercial Mexican H5N2 revealed there is no significant effect of using any type of IBD vaccines on other vaccine's immune response, although it was noticed that the mean HI titers are slightly higher in case of birds vaccinated with the subunit IBD vaccine than birds vaccinated with the conventional IBD vaccines.

In contrast, in case of using the variant $\mathrm{A} /$ chicken/Egypt/VRLCU67/2011 (H5N1) strain in the HI testing of serum samples; it revealed significant differences between chickens vaccinated with conventional IBD vaccines and the new sub-unit one. These results indicate that using of conventional IBD vaccines adversely affected the immune response of birds to AI vaccines. In addition, the difference between mean $\mathrm{HI}$ titers were noticeably high, and birds vaccinated with subunit IBD vaccines showed higher antibody levels against AI than birds vaccinated with conventional IBDV ones.

These results agree with Pitcovski et al. (2003) who mentioned that the drawbacks of using inactivated and attenuated vaccines of IBDV may be the hazard of being pathogenic due to incomplete inactivation of the virulent virus, or due to reversal to virulence of the attenuated virus. The subunit vaccine is free of this hazard since no live viruses, are involved in the production process. Also, Müller et al. (2003) stated that less attenuated strains "hot vaccines" may cause lesions in the bursa follicles and, thus, cause immunosuppression even in vaccinated birds.

Using the local A/chicken/Egypt/VRLCU67/ 2011 (H5N1) isolate in HI testing of serum samples, revealed the significant difference between the effect of both IBD vaccines on immune response of birds, in contrast to the commercial H5N2 antigen. So, it is important to use the same circulating field AI virus to make a reliable evaluation of immune status of birds.

\section{REFERENCES}

Hagag, S. Y., Awad, A. M., Arafa, A. A. 2013. Incidence of Avian Influenza Among Commercial and Native Breeds In West Delta Region. AJVS, 39 (1), 31-39.

Müller, H., Islam, Md. R., Raue, R. 2003. Research on infectious bursal disease - the past, the present and the future. Vet Microbiol. 97, 153-165.

Coletti, M., Del Rossi, E., Franciosini, M. P., Passamonti, F., Tacconi, G., Marini, C. 2001. Efficacy and Safety of an Infectious Bursal Disease Virus Intermediate Vaccine In Ovo. Avian Dis. 45:1036-1043.

OIE 2008. Infectious Bursal Disease (Gumboro disease). Chapter 2.3.12. Manual of Diagnostic Tests and Vaccines for Terrestrial Animals. p. 549.

OIE 2012. Avian influenza. Chapter 2.3.4. Manual of Diagnostic Tests and Vaccines for Terrestrial Animals. p. 444.

Pitcovski, J., Gutter, B., Gallili, G., Goldway, M., Perelman, B., Gross, G., Krispel, S., Barbakov, M., Michael, A. 2003. Development and large-scale use of recombinant VP2 vaccine for the prevention of infectious bursal disease of chickens. Vaccine; 21: 4736-4743.

Pradhan, S. N., Princea, P. R., Madhumathia, J., Royb, P., Narayanana, R. B., Antony, U. 2012. Protective immune responses of recombinant VP2 subunit antigen of infectious bursal disease virus in chickens. Vet Immunol Immunop. 148: 293- 301.

Swayne, D. E. 2006. Principles for Vaccine Protection in Chickens and Domestic Waterfowl against Avian In flue. 